\title{
Dental Aspect of Down Syndrome: A Case Report
}

\author{
Charu Thanvi ${ }^{1}$, Ashwini B Prasad ${ }^{2}$, Deepak Raisingani ${ }^{3}$, Neha Mittal $^{4}$, Akansha Jharwal $^{5}$, Asha Jetwani ${ }^{6}$
}

\begin{abstract}
Down syndrome (DS) is the most common genetic cause of significant intellectual disability in the human population. It is caused by the presence of all or a part of a third copy of "chromosome $21(47, X Y,+21$ or $47, X X,+21)$ ". In 1838, Esquirol first described this, later John Langdon Down in 1866 named this syndrome as "mongolism." These patients are associated with some medical as well as dental disorders. The oral structures that are commonly affected in patients with DS include the tongue (macroglossia), teeth (number and shape), and poor quality of alveolar and jaw bones (osteoporotic-like). This article presents a case of DS in 28-year-old male patient who had been prescribed multiple intentional root canal therapies (RCTs) in both maxillary and mandibular teeth as a part of rehabilitative treatment plan for congenitally missing teeth.

Keywords: Anesthesia, Chromosome 21 trisomy, Down syndrome, Endodontic therapy, Rehabilitation.

Journal of Mahatma Gandhi University of Medical Sciences \& Technology (2018): 10.5005/jp-journals-10057-0093
\end{abstract}

\section{INTRODUCTION}

Down syndrome (DS) is defined as a congenital, genetic disorder arising from a defect involving chromosome 21, usually an extra copy of it, causing intellectual impairment and physical abnormalities including a short stature and broad facial profile. It was named after John Langdon Down, the British physician who described this syndrome. Down syndrome is also known as trisomy 21, named by Dr Jecome Lejeune as a common chromosomal abnormality. ${ }^{1}$ The features of DS can range from mild to severe. Usually, mental and physical developments are slower in people with DS. ${ }^{2,3}$

There is a strong predisposition to cardiovascular disease, leukemia seizures, upper respiratory tract infection, infections with hepatitis B virus, Alzheimer's disease, thyroid disease, obesity, cardiac anomalies, and obstructive sleep apnea on these patients. ${ }^{4}$ Congenitally, missing teeth and delayed tooth eruption are also seen more among patients with DS. ${ }^{5,6}$ Morphologic diversity such as microdontia and peg laterals is commonly noticed in the dentition. In general, all the teeth with exception of mandibular incisors and maxillary molars are smaller in mesiodistal as well as buccolingual dimensions in comparison to normal teeth. Maxillary canines with premolars are often found to be impacted in many cases. ${ }^{7}$

Moreover, the entire craniofacial complex of such patient is smaller in size than normal individuals. Paranasal sinuses and orbital ridges are also underdeveloped, and in some cases, they might be missing too. The nasal bone is acutely angled and shorter, with an underdeveloped frontal maxillary process, giving an appearance of a retruded midface. The growth of both jaws is retarded including the ramus and the body of mandible. Maxillary and mandibular alveolar bones also present with a shorter vertical dimension. ${ }^{8}$

\section{Case Description}

A 28-year-old male patient was referred to the Department of Conservative Dentistry and Endodontics for multiple intentional Root canal therapy (RCTs) as suggested by the Department of Prosthodontics for full-mouth rehabilitation regarding the missing teeth.

On general examination, patient was short statured and had difficulty in speech with physiologically normal vitals
${ }^{1-6}$ Department of Conservative Dentistry and Endodontics, Mahatma Gandhi Medical College and Hospital, Mahatma Gandhi University of Medical Sciences and Technology, Jaipur, Rajasthan, India

Corresponding Author: Neha Mittal, Department of Conservative Dentistry and Endodontics, Mahatma Gandhi Medical College and Hospital, Mahatma Gandhi University of Medical Sciences and Technology, Jaipur, Rajasthan, India, Phone: +91 9461774344, e-mail: nehamittal1805@gmail.com

How to cite this article: Thanvi $C$, Prasad AB, Raisingani $D$, et al. Dental Aspect of Down Syndrome: A Case Report. J Mahatma Gandhi Univ Med Sci Tech 2018;3(3):108-112.

Source of support: Nil

Conflict of interest: None

(Fig. 1). On extraoral examination, patient had saddle nose deformity and midface hypoplasia with retruded mandible (Figs 2 and 3) with small anomalous molded ears (Fig. 4). The orthopantomogram (OPG) revealed exceptionally smaller sized teeth with abnormal sinus spaces and multiple congenitally missing teeth (Fig. 5). Intraorally, high-arch palate (Fig. 6) and macroglossia of the tongue (Fig. 7) were present along with

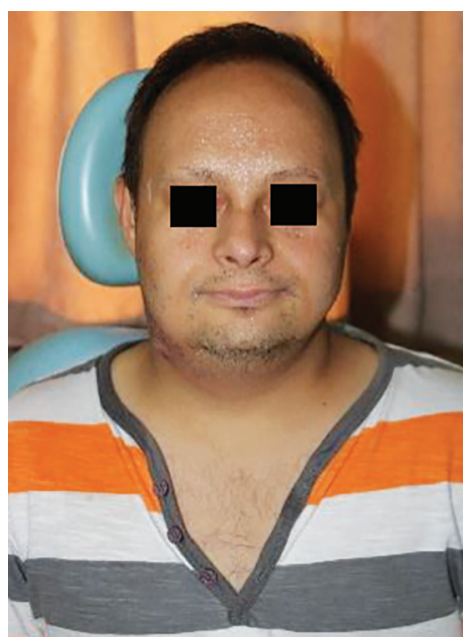

Fig. 1: General profile

() The Author(s). 2018Open Access This article is distributed under the terms of the Creative Commons Attribution 4.0 International License (https://creativecommons. org/licenses/by-nc/4.0/), which permits unrestricted use, distribution, and non-commercial reproduction in any medium, provided you give appropriate credit to the original author(s) and the source, provide a link to the Creative Commons license, and indicate if changes were made. The Creative Commons Public Domain Dedication waiver (http://creativecommons.org/publicdomain/zero/1.0/) applies to the data made available in this article, unless otherwise stated. 


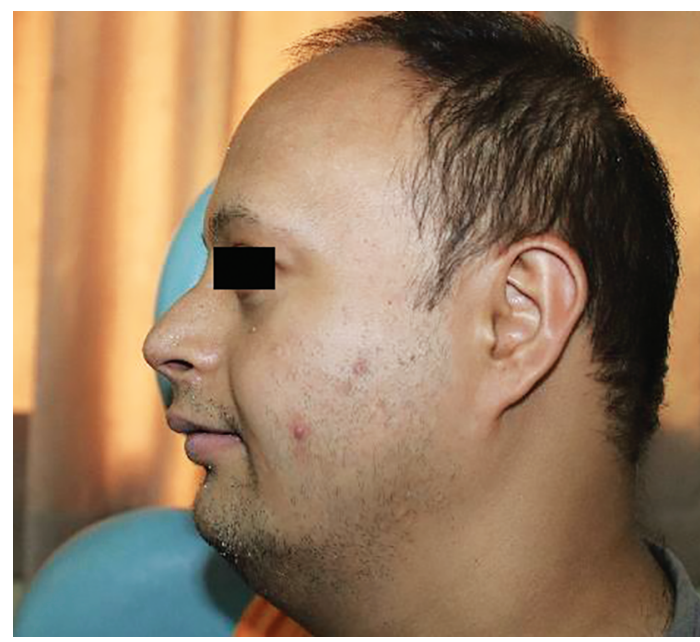

Fig. 2: Lateral profile

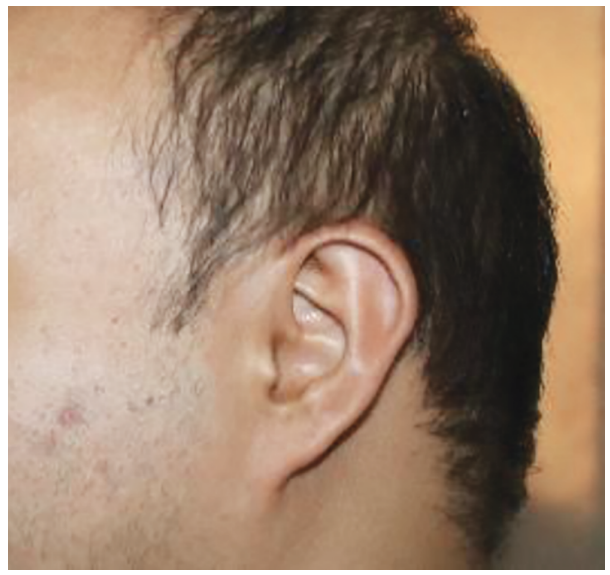

Fig. 4: Anomalous molded ears

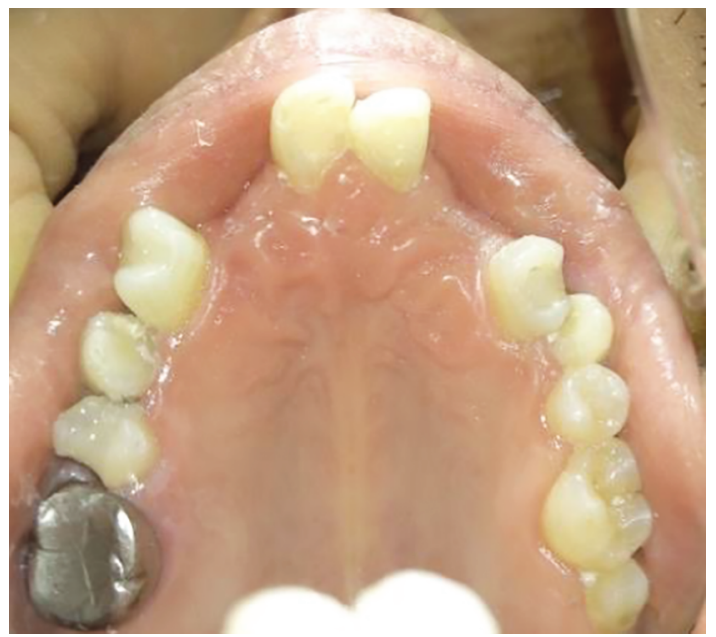

Fig. 6: Intraoral maxilla

hypodontia, microdontia, rotation of teeth, and atypical form of dental crowns with transposition of maxillary canines with first premolars (Figs 6 and 8 to 10). Nasal congestion was observed in all the appointments, and a detailed history revealed the frequent occurrence of common cold and respiratory distress.

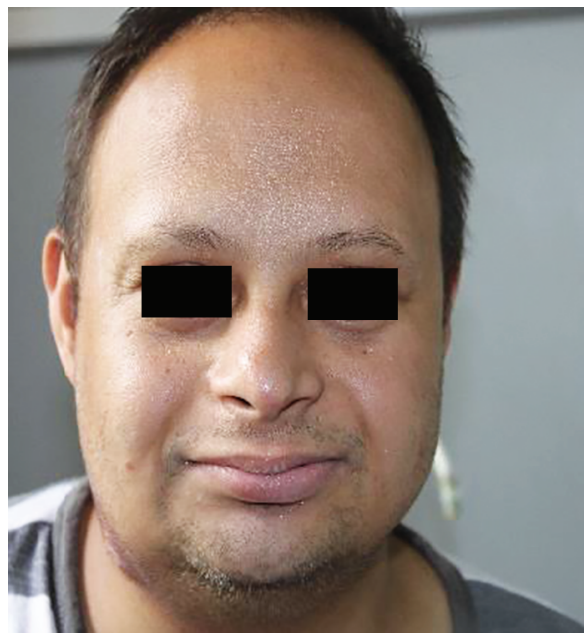

Fig. 3: Front profile

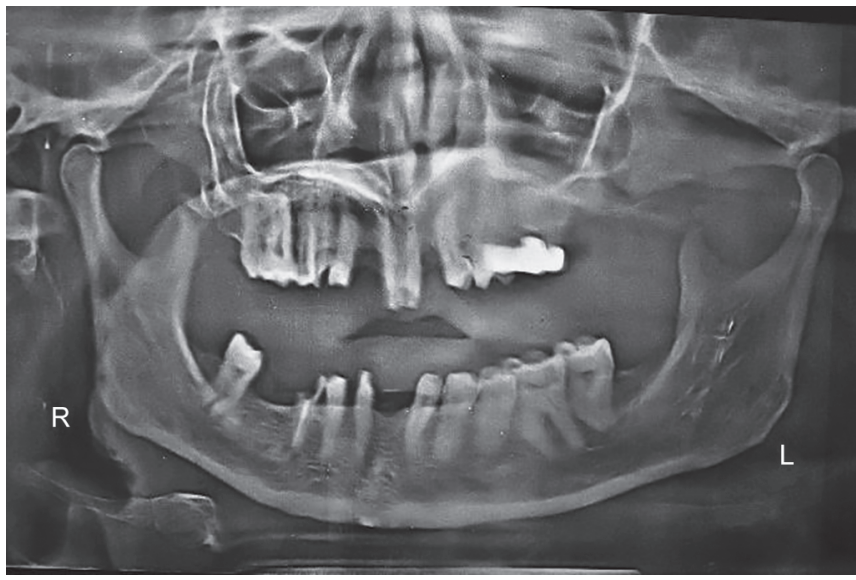

Fig. 5: Preoperative OPG

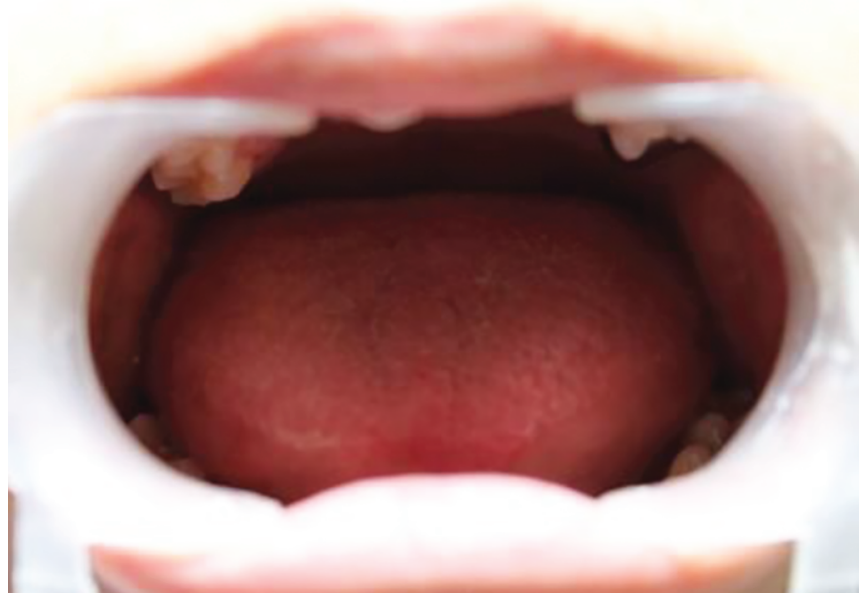

Fig. 7: Macroglossia

Behaviorally, the patient was gentle, patience, and cooperative during all the visits and had an interactive nature toward the other doctors and paramedical staff as well.

The endodontic treatment was commenced with left first premolar due to mild tenderness on percussion. 


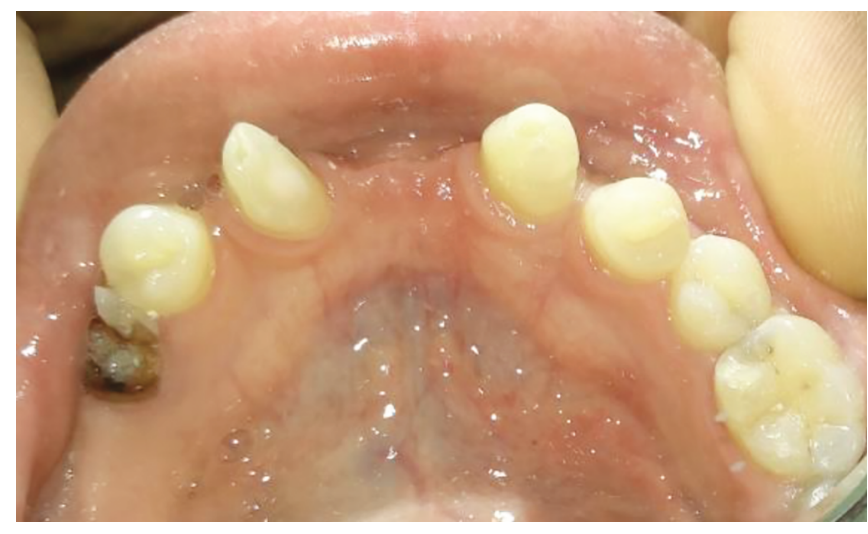

Fig. 8: Intraoral mandible

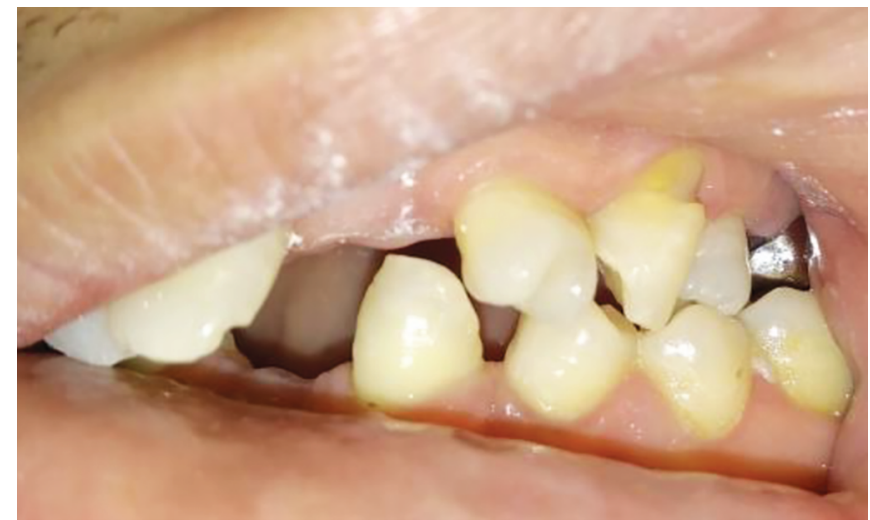

Fig. 10: Left-side occlusion

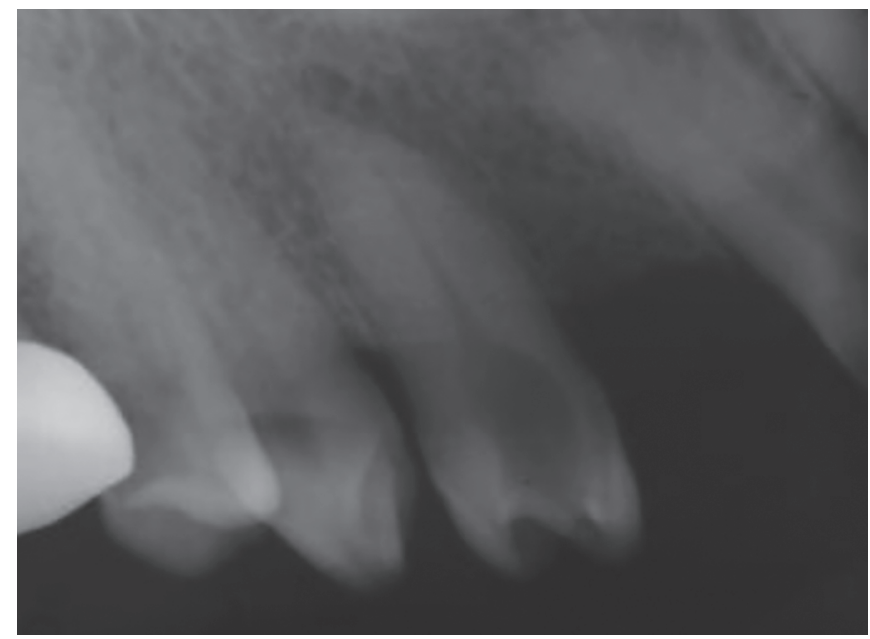

Fig. 12: Preoperative maxillary premolars

The patient was given local infiltration with $1.8 \mathrm{~mL}$ of $2 \%$ lignocaine with 1:100,000 epinephrine as it was thought to be effective due to porosity of the maxillary bone. Rubber dam isolation could not be provided due to the uneasiness experienced by patient under rubber dam sheet. After the objective symptoms were achieved, the access opening and canal tracing was performed with the help of Endo-Access Bur (Dentsply Maillefer, Ballaigue, Switzerland). In contrast to the normal anatomy, only one canal was found in the maxillary first premolar. During the

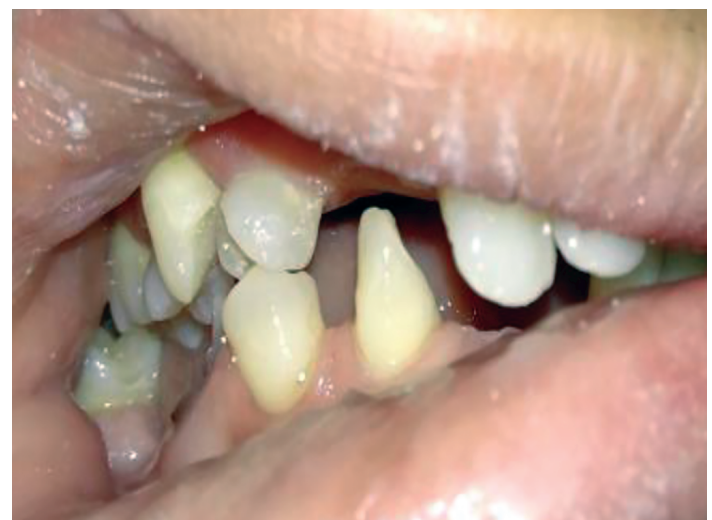

Fig. 9: Right-side occlusion

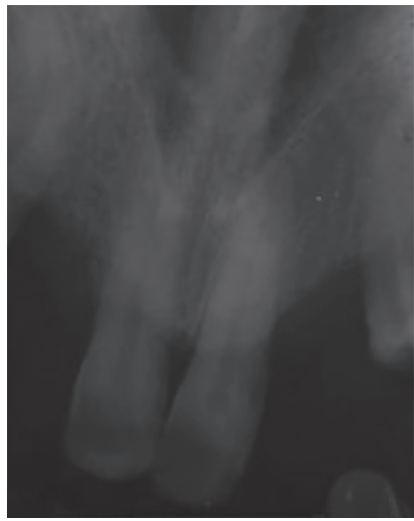

Fig. 11: Preoperative maxillary central incisors

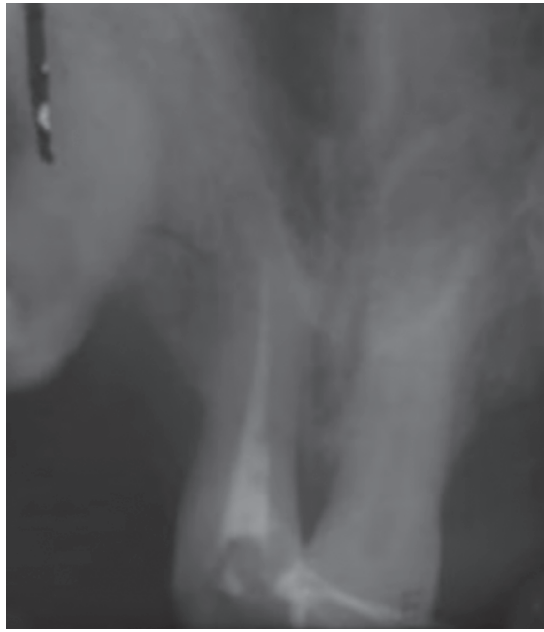

Fig. 13: Obturation-maxillary central incisor

access opening, it was found that the pulpal anesthesia has not been achieved. Infraorbital block was administered which also proved to be ineffective in obtaining desired pulpal anesthesia. Supplemental injections including the intraligamentary and intrapulpal were administered but failed to achieve the potent anesthetic effect. Due to the ineffectiveness of anesthesia, and increasing anxiety of the patient, less invasive and painless decision was made by application of a devitalizing agent over the orifice. 


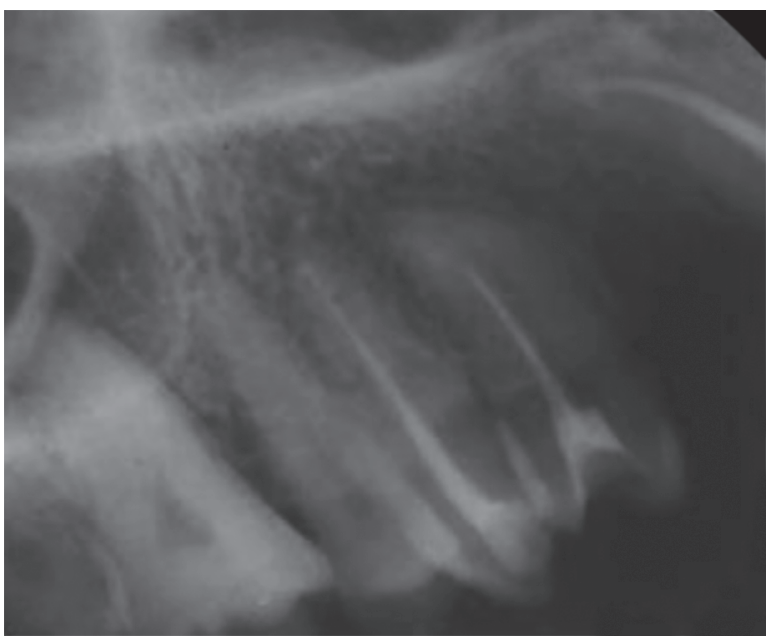

Fig. 14: Obturation-maxillary right canine and premolar

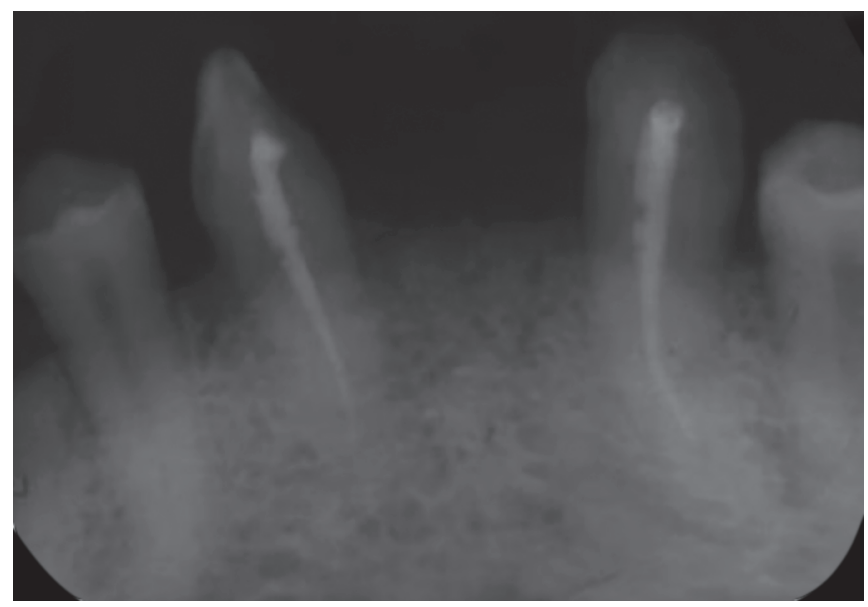

Fig. 16: Obturatio-mandibular anteriors

In the next visit, the shaping and cleaning of the canal was done using nickel-titanium rotary instruments (Sybron Endo, Orange, CA, USA). Irrigation was done with $5.25 \%$ sodium hypochlorite solution ( $\mathrm{NaOCl}$ ) and 2\% chlorhexidine (Sigma Chemicals, St. Louis, MO, USA) alternatively with sterile saline with RC-Prep (Premier Dental Products; Norrstown, PA, USA) as a lubricant. The canal was dried with sterile paper points. Following radiographic control of the fit of gutta-percha master cone (Gutta-percha; Sybron Endo), the canal was obturated with AH Plus sealer (Dentsply DeTrey, Konstanz, Germany) using a single-cone technique. The access cavity was sealed with composite resin. Rest of the teeth were treated in the same manner (Figs 11 to 16) with an interval of rest for 5-10 minutes after every half an hour of sitting to manage the behavior of the patient as well as for patient's compliance. The patient then underwent coronal prostheses and full-mouth rehabilitation.

\section{Discussion}

The incidence of DS has been reported to increase with an increasing maternal age (Niazi et al., 1995). On the contrary, the life expectancy of these individuals has appreciably increased over the past few years when compared with the older times (Horbelt, 2007; Kumar et al., 1997). Down syndrome patients are now having longer life as well as more social involvement than before which is creditable

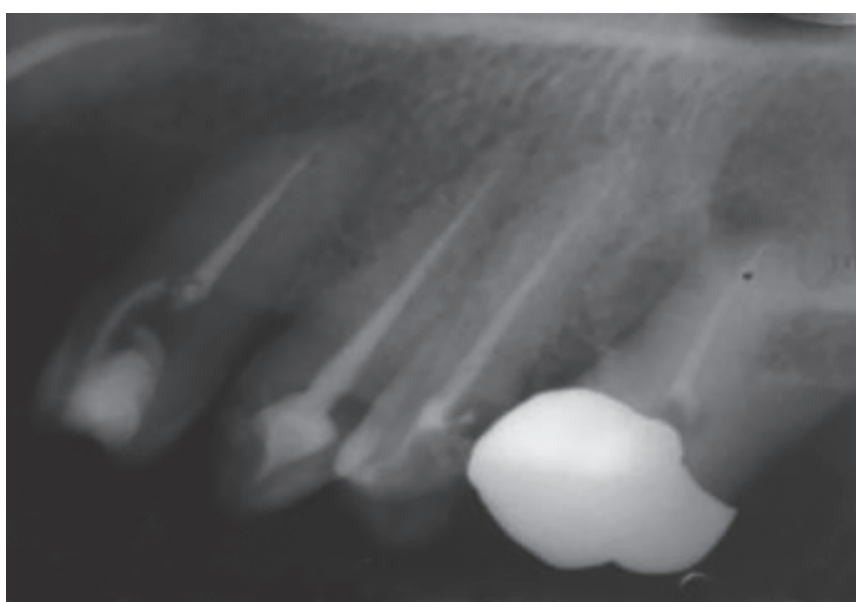

Fig. 15: Obturation-maxillary left canine and premolars

to the advanced medical healthcare facilities and awareness regarding this syndrome. In both primary and permanent teeth, dental anomalies like hypodontia, microdontia, atypical form of dental crowns, and taurodontism are very common. Their incidence is five times greater in DS individuals than in the general population. In these patients, cleft lip, cleft lip, and palate or cleft palate only occur three times more often than in the general population. An anterior open bite is normally found in the DS children; perioral muscles are affected by characteristic muscle hypotonia. Also, patients with DS can present with periodontal diseases, premature tooth loss, reduced salivary flow, crowding of teeth in both arches, and decreased occlusal vertical dimension. Regardless of increased frequency of periodontal disease, there is a reduced incidence of dental caries in these patients. Oftentimes dribbling of saliva from the corner of the mouth can be seen. ${ }^{4}$

These were most of the features present in our patient, and the clinical features coexisted with the neural symptoms as well. The congenitally missing teeth with the transpositioning and rotation of premolar and canine which made the treatment difficult from anesthetic point of view since the sensory supply to first premolar is said to be blocked with middle superior alveolar nerve block which was found to be ineffective, therefore intraligamentary and local infiltration of local anesthesia (LA) were administered. These supplemental injections only achieved a relatively mild form of anesthesia. Intrapulpal injection given after the access to the canal orifice helped was the most helpful. However, repeated Intrapulpal injections were needed to achieve complete pulpal anesthesia.

This difficulty in achieving profound anesthetic effect could be attributed to the fact that patients with DS are more sensitive to pain than other individuals. The evidence does suggest that the pain expression that appears in these patients is delayed, but, once the pain is registered, there is a magnified pain response. Concurring with the other cases of DS, our patient also had a lower pain threshold, which demanded supplemental anesthetic injections during the treatment in first, third, and fourth quadrants. On the contrary, the teeth in the second quadrant responded normally to the anesthesia. This conclusion corresponds with the brain imaging studies showing differences in structures involved in pain processing and pain modulation. ${ }^{9}$

The burs used for the modification of the access cavity were later changed to smaller size round burs due to the small mesiodistal as well as buccolingual dimensions of tooth. 
Abnormalities in size (smaller), the number (fewer teeth), and morphology (altered shape) and the timing of their development (late dentition) are constant features observed in this syndrome. Morphological abnormalities including taurodontia, peg-shaped teeth, gemination, and fusion are all interrelated and can be attributed to a reduced mitotic activity of dental progenitor cells during embryogenesis. ${ }^{10}$

The canal morphology in the maxillary first premolars also differed from the normal. In contrast to the most commonly found two roots with type IV (2-2) canal pattern, the patient had a single orifice and single canal which is a common finding in DS cases which occurs as a result of growth retardation. ${ }^{11}$ Difficulty was encountered during the cleaning and shaping of teeth due to narrow and thin root canals. Repeated recapitulation with copious irrigation and lubrication was required to negotiate the canals making the procedure time-consuming which compromised the cooperativeness of patient. A continuous half-an-hour-long sitting made the patient restless and reluctant to the treatment, requiring 5 to 10 minutes of break to receive cooperation from patient. While confirming the procedural steps with intraoral periapical radiograph, the interpretation became difficult due to the overlapping of abnormal sinus spaces and sinus lining over anatomic roots and root apex of the teeth. A significantly high prevalence of congenitally absent or abnormal frontal and maxillary air sinuses observed among the DS patients coincides with the findings. Small nose and nasal sinuses lead to increased nasal congestion obstructed sleep apnea and worsened allergies. ${ }^{12,13}$ The patient presented with persistent cold and nasal congestion, which led to frequent coughing and urged the patient to spit in short intervals during the treatment which prolonging the duration of appointment. Poorly developed air sinuses accompanying with the craniofacial radiographic findings of brachycephaly with retarded ossification along the bony sutures and calvarium thinning. ${ }^{14}$

Common characteristics observed in young DS patients have been described as gentleness in speech and natural spontaneity having patience with tolerance. These characteristics together with a rarity of significant physical disability result in many of these patients being treated easily in a general practice. ${ }^{15}$ In contrast to the positive traits described, fewer patients with DS can also exhibit anxiety, stubbornness, and resistance to change that can singly or in combination make dental care a challenging experience to the patient as well as the operator. ${ }^{16}$

Several techniques that are applied to patients with uncooperative behavior can be used in these patients too. These techniques include (1) desensitization, (2) behavior modification, (3) tell-show-do, (4) positive reinforcement and voice control, (5) mouth props, (6) intravenous or nitrous oxide sedation, and (7) use of local or general anesthesia. ${ }^{17}$

\section{Conclusion}

The presence of dental anomalies in patients with DS is quite pronounced, with an incidence of $95.92 \%$. Along with their slow growth and development, these patients present at least one type of dental anomaly. Knowledge regarding DS and its dentofacial manifestations is important not only for the early diagnosis but also for the long-term medical and dental health management of these individuals. An early recognition of such a disorder is crucial in improving the psychological, physiological, as well the medical and dental quality of life in affected patients.

\section{References}

1. Harshithaa N, Maragathavalli G. Case report Down's syndrome (trisomy 21). IOSR J Dent Med Sci 2014;13(1):03-04. DOI: 10.9790/085313170304.

2. Regezi S. Oral pathology. Clinical pathologic correlations. 1st ed., Philadelphia: Saunders; 1989. pp. 450-451.

3. Vogel F, Motulsky AGO. Human genetics, problems and approaches. 2nd ed., Springer-Verlag; 1996. p. 59.I.

4. Vesna A, Batra M. Down syndrome-an insight to dental aspect- case report. EC Dental Science 2017;14(3):150-156.

5. Mestrovic S, Mik Sic M, Stefanac-Papic J, et al. Prevalence of malocclusion in patients with Down's syndrome. Acta Stomatol Croat 2002;36(2):239-241.

6. Moraes MEL, Moraes LC, Dotto GN, et al. Dental anomalies in patients with Down syndrome. Braz Dent J 2007;18(4):346. DOI: 10.1590/S010364402007000400014.

7. Shapira J, Chaushu S, Becker A. Prevalence of tooth transposition, third molar agenesis, and maxillary canine impaction in individuals with Down syndrome. Angle Orthod 2000;70(4):290. DOI: 10.1043/00033219(2000)0702.0.CO;2.

8. Mubayrik $A B$. The dental needs and treatment of patients with Down syndrome. Dent Clin N Am 2016;60(3):613-626. DOI: 10.1016/ j.cden.2016.02.003.

9. McGuire BE, Defrin R. Pain perception in people with Down syndrome: a synthesis of clinical and experimental research. Front Behav Neurosci 2015;9:194. DOI: 10.3389/fnbeh.2015.00194.

10. Desai SS. Down syndrome A review of the literature. Oral Surg Oral Med Oral Pathol Oral Radiol Endod 1997;84(3):279-285. DOI: 10.1016/ s1079-2104(97)90343-7.

11. Kelsen AE, Love RM, Keiser JA, et al. Root canal anatomy of anterior and premolar teeth in Down syndrome. Int Endod J 1999;32(3):211-216. DOI: 10.1046/j.1365-2591.1999.00223.x.

12. Spitzer R, Robinson MI. Radiological changes in teeth and skull in mental defectives. Br J Radiol 1955;28(327):117-127. DOI: 10.1259/00071285-28-327-117.

13. Bhattarai B, Kulkarni AH, Rao ST, et al. Anesthetic consideration in Downs syndrome-a review. Nepal Med Coll J 2008;10(3):199-203.

14. Al-Shawaf R, Al-Faleh W. Craniofacial characteristics in Saudi Down's syndrome, King Saud University. J Dent Sci 2011;2:17-22.

15. Pueshel SM. The person with Down syndrome: medical concerus and educational strategies. In: Lott I, McCoy E. Down syndrome advances in medical care. New York: WileyLiss; 1992. pp. 53-60.

16. Davila JM, Restraints and sedation of the dental patient with developmental disabilities. Special Care Dentistry. Nov-Dec 1990; Conference paper: pp. 210-212.

17. Troutman KC. Behavior of children in the dental office. Update Pediatr Dent 1988;1(4):1-6. 